\title{
Prevalence on the complement in offering food to newborns
}

Josilene Maria Ferreira Pinheiro 1

(iD https://orcid.org/0000-0003-0564-4828

Taiana Brito Menêzes Flor 2

(iD https://orcid.org/0000-0001-5164-8446

Amanda Michelly Braga da Mata 3

iD https://orcid.org/0000-0001-7388-3500

Vanessa Cristina da Costa Pires 4

(iD) https://orcid.org/0000-0002-6725-2515

Luana Isabelly Carneiro de Oliveira 5

(iD https://orcid.org/0000-0003-4170-0559

\author{
Wanessa Pinheiro de Macedo Barbosa 6 \\ (iD https://orcid.org/0000-0001-5022-4107 \\ Fábia Barbosa de Andrade 7 \\ iD https://orcid.org/0000-0002-7055-8726
}

1,2,7 Programa de Pós-Graduação em Saúde Coletiva.Universidade Federal do Rio Grande do Norte. Av. Senador Salgado Filho, 1787. Lagoa Nova. Natal, RN, Brasil. CEP: 59.056-000. E-mail: josilenemfp@gmail.com

3 Hospital Universitário Onofre Lopes. Natal, RN, Brasil.

4,5 Departamento de Nutrição. Universidade Federal do Rio Grande do Norte. Natal, RN, Brasil.

6 Departamento de Medicina. Universidade Federal do Rio Grande do Norte. Natal, RN, Brasil.

\begin{abstract}
Objectives: to identify the prevalence and determining factors of the complements in offering food to newborns.

Methods: across-sectional study nested to a cohort study that assessed newborn care in four public maternity hospitals in Natal/Brazil. Sample was composed by 415 mothers and full-term newborns, with appropriate weight for gestational age and Apgar scores in 1st and 5th minutes $\geq 7$. In order to analyze the determining factors, we used Poisson's regression.

Results: from 415 newborns, $51.3 \%$ received feeding complements $(57.6 \%$ in the first hour of life), of which $92 \%$ was infant formula. Only $50.7 \%$ of those complement in offering food were prescribed by physicians. Colostrum deficiency was the main reason to be indicated (33.8\%). Maternal age $\leq 20$ years old $(P R=0.64 ; C 195 \%=0.47-0.86)$ and between 20 30 years old $(P R=0.70 ; C 195 \%=0.57-0.87)$ comparing to women older than 30 were shown as protective factors, while being primiparous $(P R=1.37$; $C 195 \%=1.11-1.60)$ and had cesarean section ( $P R=1.2 ; C 195 \%=1.00-1.45)$ as risk factors.

Conclusion: maternal characteristics are associated with the complement in offering food to the newborn in the first hours of life. The high prevalence shows the need for interventions that minimize the inadequate offer of infant formula and promote exclusive breastfeeding before hospital discharge.

Key words Infant nutrition, Infant formula, Breastfeeding, Weaning, Complementary feeding
\end{abstract}

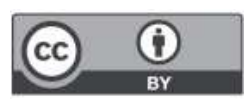




\section{Introduction}

Exclusive Breastfeeding (EB) - which should be offered from birth to the first 6 months of life - is among the World Health Organization recommendations for reducing child mortality. 1-3 Studies show that the chances of remaining in breastfeeding (BF) in the first month and in the following months are greater when the newborn (NB) is placed in immediate contact with the mother, skin-to-skin, and even more when it is possible to accomplish the "Golden Hour". This consists in placing the NB on the maternal breast in the first hour of life. ${ }^{4}$

In this context, the Iniciativa Hospital Amigo da Criança (IHAC) (Child-Friendly Initiative Hospital), which was established in Brazil in the 1980 s, advocates a prevalence above $80 \%$ for breastfeeding in the first hour, and acts to protect and promote breastfeeding, such as the "Ten Steps for Successful Breastfeeding". Among them are steps 4 -"To help mothers start breastfeeding in the first half hour after the baby's birth" - and 6 -"To avoid giving the newborn any food or drink other than breast milk, unless this procedure has a medical indication". 4 Other highlights are the Programa Nacional de Incentivo ao Aleitamento Materno (National Program to Encourage Breastfeeding), the installation of Human Milk Banks (HMB), the Estratégia Amamenta e Alimenta Brasil (Brazilian Breastfeeding and Food Strategy) and the legislation on breast milk substitutions. 5,6

Despite the efforts to maintain EB, the offer of a complement, predominantly with infant formula, is a frequent practice and without justifying reasons for IHAC in the first hours of life of low-risk NB. ${ }^{7,8}$ The following conditions stand out as justifying reasons: Premature NB, with very low birth weight, who are at risk of hypoglycemia, situations that contraindicate breast milk, and in the mother's adverse clinical conditions which prevent breastfeeding. 4

The prevalence of supplement of offering is still high, reaching around $75 \%$ in some countries and from $16 \%$ to $63.5 \%$ in different Brazilian regions. ${ }^{9-}$ 17 Difficulties in gripping and sucking, NB has hypoglycemia, skin to skin contact after birth, breastfeeding in the first hour of life, type of delivery, maternal clinical and sociocultural characteristics, lack of guidance from the professionals and the lack of accreditation of the maternity hospital to the IHAC are among the factors that are commonly associated with early offering of the complement. 10,11,13-17

Another concerning factor has been the increased offer of milk formulas due to the shortage of pasteurized breast milk in the HMB. This practice, in turn, has been related to the increased risk of intestinal dysbiosis, infections and allergy due to the cow's milk protein in NBs. ${ }^{14,18}$ It is known that breast milk is rich in essential amino acids, growth factors, immunoglobulins, probiotics, among other essential substances for neonatal development.

Considering that indiscriminate the complement in offering food is among the causes that compromise breastfeeding substantially in the first hours and days after birth, this study aims to identify the prevalence of offering complementary food to NBs and the factors associated with this practice.

\section{Methods}

A cross-sectional study nested with a cohort study that assessed neonate care in four public maternity hospitals in the city of Natal, in the state of Rio Grande do Norte (Northeast Brazil), from February to August 2019. The aforementioned city represents a percentage of $42 \%$ of live births in the State with its greatest representation in maternity hospitals linked to the Public Health System (SUS).

The calculation of the representative sample in the main study considered a prevalence of $70 \%$ in the performance of care actions, a sampling error of $5 \%$ for a population of 14,025 live births in 2018 , a $95 \%$, of confidence interval and non-response rate of $24 \%$, resulting in a sample size of 415 mother/child binomials. This total was stratified according to the percentage of live births in 2018 in the four selected public maternity hospitals (Figure 1).

Recruitment and data collection were performed daily (except for some days of the weekend), during daytime hours, for 1 to 2 months in each maternity hospital, totaling a period of 7 months from the beginning to the end of the collection, according to established criteria. Initially, medical records were consulted to identify infants who met the following eligibility criteria: live term newborns ( $\geq 37$ weeks), with birth weight $\geq 2,500 \mathrm{~g}$, Apgar scores at the 1 st and $5^{\text {th }}$ minute $\geq 7$, and from a single pregnancy. After that, puerperal women were invited to participate in the study, and in case of acceptance, the Informed Consent Form (ICF) was applied. Mothers who were not in good health to answer the research instrument did not meet the inclusion criteria. The interview with the mother was carried out using a questionnaire tested in a pilot study and applied by a team of previously trained researchers. For this study, some variables (actions) were used and collected in the first follow-up interview, was conducted 48 hours after delivery. When the infor- 


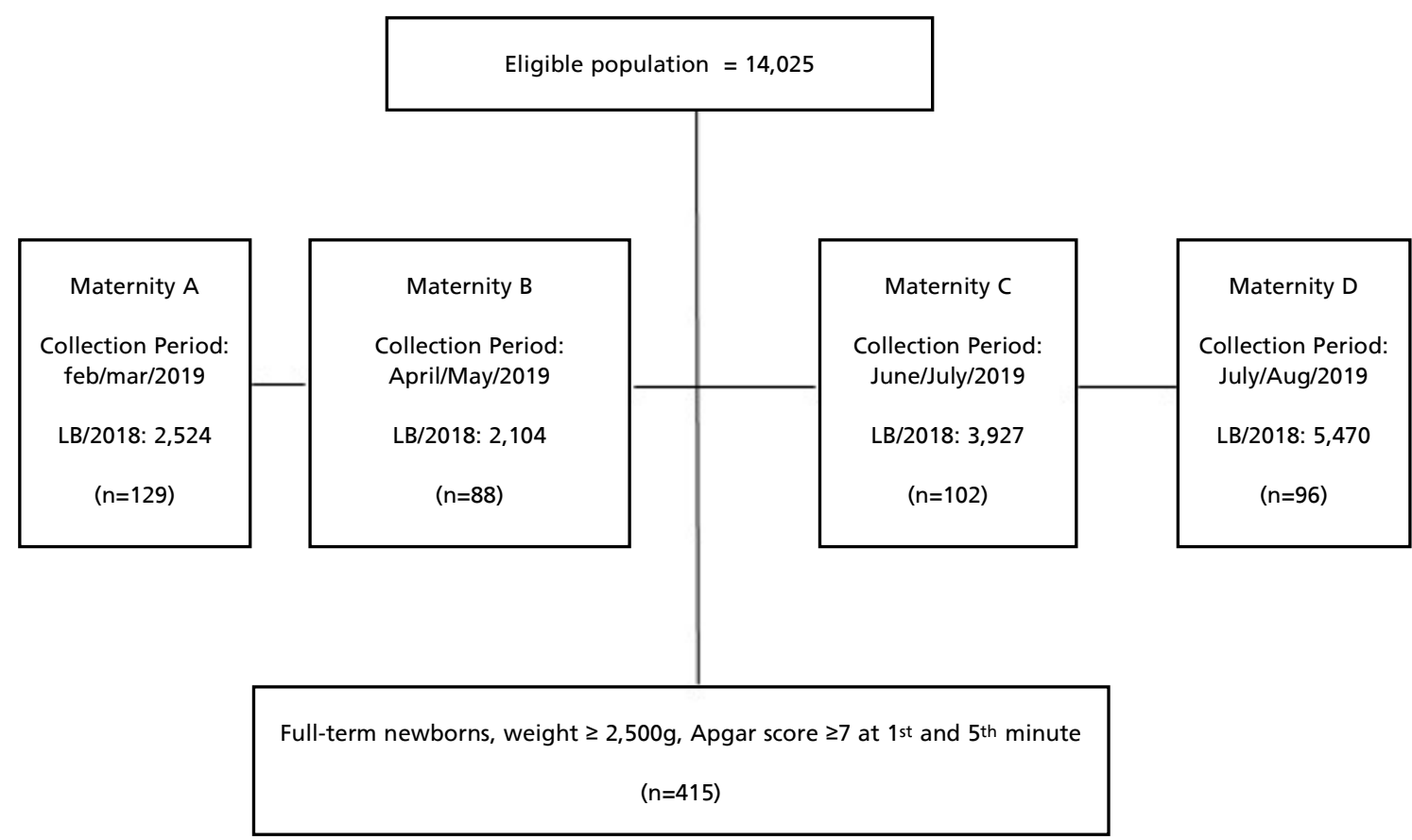

$\mathrm{LB}=$ Live births. Data provided by the Secretaria Estadual de Saúde (State Health Secretary).

mation was not written in the medical record, it was asked directly from the mother.

The dependent analyzed variable was the complement inoffering food during the NB's hospitalization until the moment of the interview. The complement is characterized by the offering of pasteurized maternal milk or infant formula in the absence of the first one, under different conditions. The prescriptions, indications, type, volume and time of the offer were also assessed.

The explanatory variables, characterized as possible determinants for the complement in offering food in a room setting were those related to the maternal individual characteristics (age, schooling, income, parity, clinical condition of clinical diabetes, type of delivery, intention in breastfeeding), the NB's characteristics and clinical condition (sex, weight at birth and glycemic values before the complement in offering food ); the welfare variables (companion during the delivery process, skin-to-skin contact and breastfeeding in the first hour of life) and the institutional variables (administrative nature of the maternity, level of complexity, "Child-
Friendly" title given by the IHAC and number of professionals per bed).

The statistical analysis of the data was performed through the SPSS ${ }^{\circledR}$ Statistical Program, version 20.0. The association between independent and dependent variables was made by the means of Pearson's Chisquare test and the Linear Trend test to compare the groups that received or not the complement, in addition to the Student's T test for quantitative variables with normal distribution. The joint effect of variables associated with was evaluated by the Poisson Regression. Initially, the independent variables with $p$ value $\leq 0.20$ in Pearson's Chi square were eligible. In the next block, the inclusion of variables was by the main effects method, individually removing the variables with $p$ value $<0.10$. In the final model, the explanatory variables with $p$ value $\leq 0.05$ and $95 \%$ confidence interval were considered, which met the established assumptions for fit (Goodness off fit), significance (Omnibus Test) and dispersion.

The ethical approval was granted by the Research Ethics Committee from the Hospital Universitário Onofre Lopes, under the opinion 
number 3.133217, being in line with Resolution number $466 / 2012$, which contemplates guidelines and regulatory norms for the research with human beings. If the participant was under 18 years old, the consent was obtained from parents or guardian on his/her behalf.

\section{Results}

A total of 415 mother-child pairs were recruited (Figure 1), with a $16.6 \%$ loss at the end of the 28-day follow-up of the cohort that originated this study. There were no mothers who refused to participate in the study. Thus, of the 415 mother-child binomials recruited, $213(51.3 \%)$ NB received complementation. Table 1 shows the care, maternal, and neonatal characteristics. Mothers were predominantly 20 to 29 years old $(46.5 \%)$, had attended high school $(60 \%)$, were married or in a stable union, with a family income less than or equal to one minimum wage, and were multiparous. As for the NB, 52.5\% were male and $90.4 \%$ were born weighing between 2,500 and 4,000 grams, whose mean weight was $3,324 \mathrm{~g}$, with a standard deviation of $478.6 \mathrm{~g}$.

The maternal characteristics initially revealed a significant association $(p \leq 0.05)$ for offering maternal milk as a complement. Nevertheless, after multiple analysis, the complement in offering food remained significantly associated with variables related to age, parity and type of delivery. When analyzing each explanatory variable individually, the maternal age $\leq 20$ years old showed a protective effect in $36 \%$ and age between 20 and 29 years old protective effect of $30 \%$. When it was considered only the predictive factors, the prevalence increases $1.37(\mathrm{CI}=1.11-1.60)$ and $1.20(\mathrm{CI}=1.00-1.45)$ times, respectively for primiparity and cesarean delivery (Table 1).

Table 2 shows the distribution of the use of the complement based on the variables that characterize the institutions. Similar results are observed in both groups, with no statistically significant difference $(p>0.05)$ when evaluating the administrative nature, level of complexity, IHAC title and the ratio of number of professionals per bed.

Of the $213(51.3 \%)$ NBs that received complement, $57.6 \%$ was in the first hour of life and, the mean of $5.6 \pm 7.2$ hours after birth. As for the type of complement offered, $92 \%$ had infant formula. Of the total of NBs that received the complement, only half had a medical prescription. The main reason described in the medical record or informed by the mother was the absence or deficiency of colostrum $(33.8 \%)$, while $23.9 \%$ had no reason for the indica- tion (Table 3).

\section{Discussion}

In this study, a high prevalence of complementary feeding was found, which corroborates the findings of studies conducted in Ireland, Canada, the United States, and even Brazil.2,14,15,19 Although, WHO recommends skin-to-skin contact at birth, breastfeeding in the first hour of life and "Do not give the newborn baby any food or drink other than breast milk, unless such procedure has a medical indication", most NBs received the complement in the first hours and days after birth. We even found that this offer occurred without any justifiable indication on the part of IHAC and often without a medical prescription.

The actions instituted by the United Nations Children's Fund and WHO, through IHAC, have contributed to the success of breastfeeding and to the reduction of the complement of offering food. 4,20 which differs from the results introduced in this research. Among the participating institutions, only one did not have the title named "Child-Friendly Hospital". Nevertheless, maintaining this title did not favor the achievement of differentiated outcomes. Even with the advances and achievements obtained by accredited institutions in Brazil, practical and operational difficulties are observed in enforcing the "Ten Steps", especially step 6.20

The administrative nature, the level of complexity and the ratio of the number of professionals per bed did not influence the complement in offering food. These findings differ from those obtained by studies in the United Kingdom, whose lack of personnel, perception of the importance of support and professionals' qualification were associated with the complement in offering infant formulas. 12

The maternal age under 29 years behaved as a protective factor to the complement in offering food to NBs, opposing the Australian study developed by Bentley et al., ${ }^{17}$ which identified younger mothers as more likely to give infant formula to their NBs. Such protection can be justified by a probable reverse causality, so that, possibly, the most vulnerable women may have received priority care from the healthcare team, which is a conduct recommended by WHO.

Conversely, the prevalence of this offer was increased by 1.37 times for NBs of primiparous mothers, being consistent with the pertinent literature.10,17 This vulnerability can be justified by the absence of previous breastfeeding, 16,21 inadequate 
milk perception, pain, breast milk problems 22 and cesarean section. The latter was associated to a $20 \%$ increase in the prevalence of complement, corroborating the findings in the pertinent literature. 17 Knowing that $46 \%$ of the children in this study were born from cesarean section -higher than the recommendation by WHO $(10 \%)$ in reducing maternal and neonatal mortality -such association is a concern. Brazil has implemented public policies that, in addition to contributing in the reduction of unnecessary interventions to the mother-child binomial, also aiming to improve breastfeeding indicators from their promotion. Among them, we can highlight the Rede Cegonha (Stork Network), the Apice-On qualification and the IHAC. 1,23

In this study, the main reason for supplementation was the absence of colostrum. However, this does not fit as an acceptable medical reason. Conversely, only $42.3 \%$ showed clinical conditions justifiable through IHAC (deficiency of grabbing and suction, large NB for gestational age, among other reasons related to the clinical conditions of the NBs and mothers). 4 This finding was higher than the one found in Biggs et al. 12 study in the UK, which found a prevalence of $10 \%$; and Pinheiro et al. 8 developed in another maternity hospital in the state of Rio Grande do Norte/Brazil, found only $6.2 \%$ of the prevalence for reasons justifiable by IHAC.

It is also noteworthy the absence of record about the reasons for such prescription in the medical records and the absence of the medical prescription itself in almost half of the sample. This is a common practice already reported in the pertinent literature. 8,10 Whether it is by verbal guidance from the

\section{Table 1}

Maternal, newborns, and healthcare teams' characteristics associated with the complementary of offering food. Natal/Brazil, 2019.

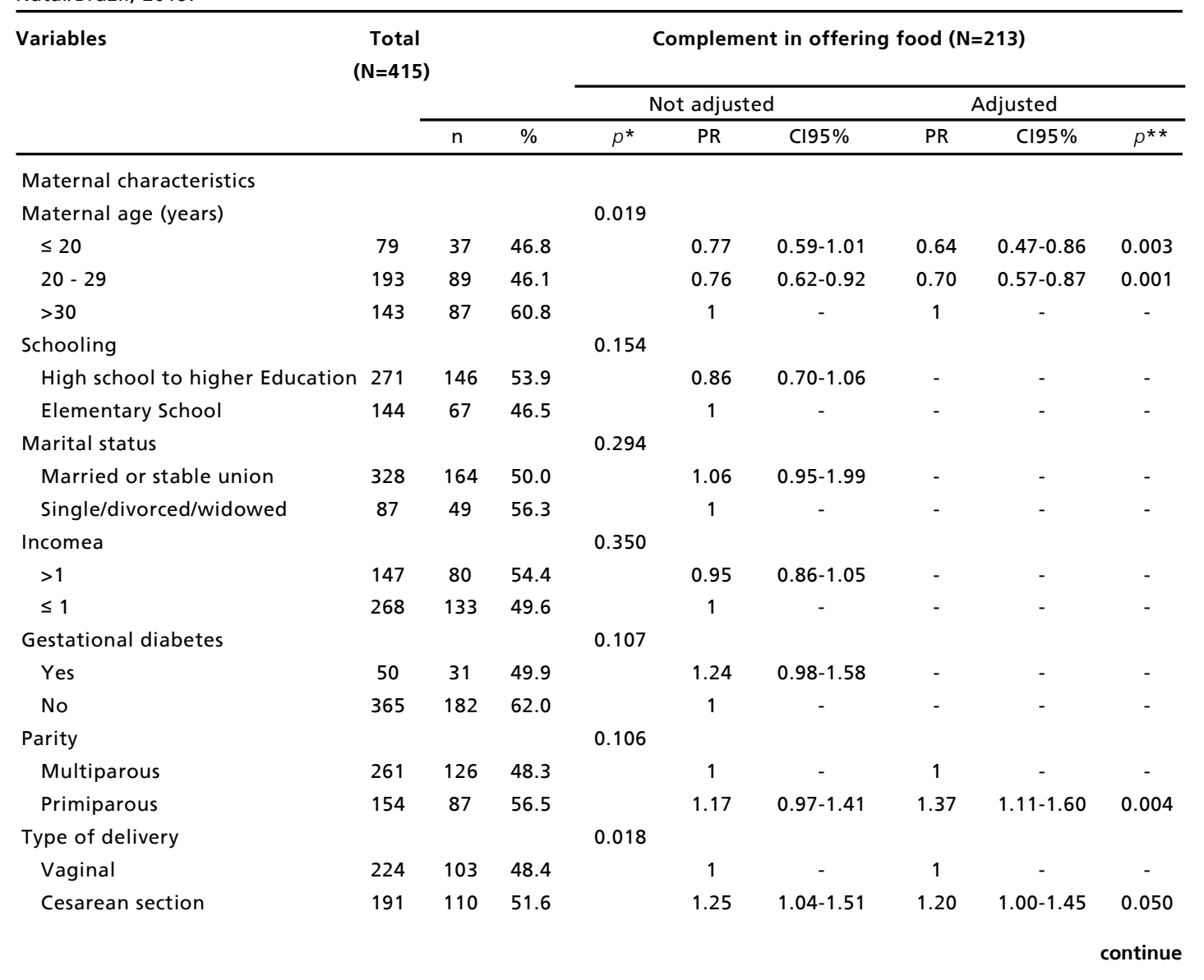

a Minimum wage (2018)= R\$998.00;bVariable collected in 3 maternity hospitals; cSample with 407 weight records; dVariable collected in 3 maternity hospitals $(n=296 / 415(23.4 \%)$, and not included in the Regression model; Variables included in the adjusted model: variables with $\mathrm{p}$ value $<0.20$.

$\mathrm{NB}=$ newborn; $\mathrm{BF}=$ breastfeeding; $\mathrm{PN}=$ Prenatal care; $\mathrm{BM}=$ breast milk; $\mathrm{g}=$ grams. $\mathrm{Mg} / \mathrm{dL}=\mathrm{milligrams} / \mathrm{deciliters}$.

$\mathrm{PR}=$ prevalence ratio; $\mathrm{Cl}=$ confidence interval; $p \leq 0.05 ; p^{*}$ Pearson's Chi-square; $p * *$ Poisson Regression. 
Maternal, newborns, and healthcare teams' characteristics associated with the complementary of offering food. Natal/Brazil, 2019.

\begin{tabular}{|c|c|c|c|c|c|c|c|c|c|}
\hline \multirow[t]{3}{*}{ Variables } & \multirow{3}{*}{$\begin{array}{r}\text { Total } \\
(\mathrm{N}=415)\end{array}$} & & & \multicolumn{5}{|c|}{ Complement in offering food $(\mathrm{N}=213)$} & \multirow[b]{3}{*}{$p^{* *}$} \\
\hline & & & & \multicolumn{3}{|c|}{ Not adjusted } & \multicolumn{2}{|c|}{ Adjusted } & \\
\hline & & $\mathrm{n}$ & $\%$ & $p^{*}$ & PR & $\mathrm{Cl} 95 \%$ & PR & $\mathrm{Cl} 195 \%$ & \\
\hline Intention to breastfeedb & & & & 0.945 & & & & & \\
\hline Up to 6 months & 83 & 43 & 50.0 & & 0.99 & $0.86-1.13$ & - & - & - \\
\hline 7 to 12 months & 70 & 35 & 50.0 & & 0.99 & $0.85-1.14$ & - & - & - \\
\hline For more than 12 months & 123 & 64 & 52.0 & & 1 & - & - & - & - \\
\hline Characteristics of NB & & & & 0.182 & & & & & \\
\hline \multicolumn{10}{|l|}{ Child's sex } \\
\hline Male & 218 & 117 & 53.7 & & 1.05 & $0.95-1.16$ & - & - & - \\
\hline Female & 197 & 96 & 48.7 & & - & - & - & - & - \\
\hline Birth weight $(\mathrm{g}) \mathrm{c}$ & & & & 0.098 & & & & & \\
\hline $2,500-4,000$ & 375 & 189 & 50.4 & & 1 & - & - & - & - \\
\hline$>4,000$ & 32 & 21 & 65.6 & & 1.32 & $0.99-1.71$ & - & - & - \\
\hline Pre-supplemental glycemiad & & & & 0.005 & & & & & \\
\hline$<40 \mathrm{mg} / \mathrm{dL}$ & 29 & 28 & 96.6 & & 1,36 & $1,14-1,63$ & - & - & - \\
\hline $40-50 \mathrm{mg} / \mathrm{dL}$ & 36 & 31 & 86.1 & & 1.23 & $1.00-1.50$ & - & - & - \\
\hline$>50 \mathrm{mg} / \mathrm{dL}$ & 32 & 21 & 65.6 & & 1 & - & - & - & - \\
\hline \multicolumn{10}{|l|}{ Health care characteristics } \\
\hline Companion during delivery & & & & 0.087 & & & & & \\
\hline Yes & 307 & 151 & 49.2 & & 1 & - & - & - & - \\
\hline No & 108 & 62 & 57.4 & & 1.17 & $0.96-1.42$ & - & - & - \\
\hline Skin-to-skin contact & & & & 0.651 & & & & & \\
\hline Yes & 246 & 124 & 50.4 & & 1 & - & - & - & - \\
\hline No & 169 & 89 & 52.7 & & 1,02 & $0.93-1.13$ & - & - & - \\
\hline \multicolumn{10}{|c|}{ Breastfeeding in the first hour of } \\
\hline life & & & & 0.036 & & & & & \\
\hline Yes & 242 & 114 & 47.1 & & 1 & - & - & - & - \\
\hline No & 172 & 99 & 57.6 & & 1.22 & $1.01-1.47$ & - & - & - \\
\hline
\end{tabular}

a Minimum wage $(2018)=R \$ 998.00$; bVariable collected in 3 maternity hospitals; cSample with 407 weight records; dVariable collected in 3 maternity hospitals $(n=296 / 415(23.4 \%)$, and not included in the Regression model; Variables included in the adjusted model: variables with $p$ value $<0.20$.

$\mathrm{NB}=$ newborn; $\mathrm{BF}=$ breastfeeding; $\mathrm{PN}=$ Prenatal care; $\mathrm{BM}=$ breast milk; $\mathrm{g}=$ grams. $\mathrm{Mg} / \mathrm{dL}=\mathrm{milligrams} / \mathrm{deciliters}$.

$\mathrm{PR}=$ prevalence ratio; $\mathrm{Cl}=$ confidence interval; $p \leq 0.05 ; p^{*}$ Pearson's Chi-square; $p * *$ Poisson Regression.

physician, pressure from the family, or by their own decision, it is possible that the nursing team requests the supplement at the lactation department, as found in Pinheiro et al. 8 study This is a situation that can result from work overload, the reduced number of professionals per bed, the lack of training of the team and the level of complexity in care. However, these factors were not determinant in this study.

Although, the indication criteria are strictly defined in order to keep NBs on EB, the occurrence of hypoglycemic episodes is a constant concern for the healthcare team. The mother's desire to offer the complement on these occasions has increased the chances of the team to applysuch conduct. 24 In order to make the mother able to experience this process without the NB using a complement, the support of the ideally trained multi-professional team is essential, which must be engaged and follow the guidelines of the "Ten Steps for Successful Breastfeeding" both in the delivery room and in the rooming. Breastfeeding in the first hour of life, as well as the guidelines on breastfeeding techniques and the characteristics and benefits of breastfeeding, enable maternal empowerment and are fundamental in reassuring the mother. Thus, it is possible to achieve emotional balance, lactogenesis is favored, the 
Table 2

Bivariate analysis of institutional characteristics and the complementary in offering food to newborn.Natal/Brazil, 2019.

\begin{tabular}{|c|c|c|c|c|c|c|}
\hline \multirow[t]{3}{*}{ Variables } & \multirow{3}{*}{$\begin{array}{l}\text { Total } \\
(\mathrm{N}=415)\end{array}$} & \multicolumn{4}{|c|}{ Complement in offering food $(\mathrm{N}=213)$} & \multirow[t]{3}{*}{$p$} \\
\hline & & \multicolumn{2}{|c|}{ Yes } & \multicolumn{2}{|c|}{ No } & \\
\hline & & $\mathrm{n}$ & $\%$ & $\mathrm{n}$ & $\%$ & \\
\hline Administrative nature of the maternity ward & & & & & & $0.346^{a}$ \\
\hline City & 190 & 91 & 47.9 & 99 & 52.1 & \\
\hline State & 96 & 54 & 56.2 & 42 & 43.8 & \\
\hline Federal & 129 & 68 & 52.7 & 61 & 47.3 & \\
\hline Level of complexity & & & & & & $0.199 b$ \\
\hline Low risk & 190 & 91 & 47.9 & 99 & 52.1 & \\
\hline High risk & 225 & 122 & 54.2 & 103 & 45.8 & \\
\hline IHAC Title & & & & & & $0.936 \mathrm{~b}$ \\
\hline Yes & 313 & 161 & 51.4 & 152 & 48.6 & \\
\hline No & 102 & 52 & 51.0 & 50 & 49.0 & \\
\hline Ratio number of professionals per bed $(\bar{X} \pm S D)$ & & & $5 \pm 0.04$ & & & $0.971 \mathrm{c}$ \\
\hline Ratio number of pediatricians per bed $(\bar{X} \pm S D)$ & & & $3 \pm 0.02$ & & & $0.875 c$ \\
\hline
\end{tabular}

IHAC = Child-Friendly Initiative Hospital; SD= standard deviation; a Linear Trend; bPearson's Chi-square; cStudent's Ttest.

Table 3

Reasons to indicate and characterize the complement in offering food to NBs. Natal/Brazil, 2019. $(n=213)$.

\begin{tabular}{|c|c|c|c|}
\hline Variables & $\mathbf{N}$ & $\%$ & $\mathrm{Cl} 195 \%$ \\
\hline \multicolumn{4}{|l|}{ Reason to offer complements to NB } \\
\hline Colostrum deficiency & 72 & 33.8 & $27.5-40.2$ \\
\hline Difficulty in grabbing /sucking & 50 & 23.5 & $17.8-29.2$ \\
\hline LGA & 7 & 3.3 & $0.9-5.7$ \\
\hline Other problems related to the NB & 18 & 8.5 & $4.7-12.2$ \\
\hline Other maternal problems & 15 & 7.0 & $3.6-10.5$ \\
\hline Without prescribed reasons & 51 & 23.9 & $18.2-29.7$ \\
\hline \multicolumn{4}{|l|}{ Medical prescription of the complement } \\
\hline Yes & 108 & 50.7 & $44.0-57.4$ \\
\hline No & 105 & 49.3 & $42.6-56.0$ \\
\hline \multicolumn{4}{|c|}{ Time of the complement offered to NB $(n=148)^{a}$} \\
\hline Morning (6:00 a.m. to 6:00 p.m.) & 76 & 35.7 & $29.0-42.0$ \\
\hline Night (6:00 p.m. to 6:00 a.m.) & 72 & 37.8 & $27.0-40.0$ \\
\hline \multicolumn{4}{|l|}{ Type of complement } \\
\hline Pasteurized breast milk & 17 & 8.0 & 43.3-59.4 \\
\hline Infant formula & 196 & 92.0 & $40.6-56.7$ \\
\hline \multicolumn{4}{|l|}{ Complement volume offered } \\
\hline$\leq 10 \mathrm{~mL}$ & 174 & 81.7 & $76.5-86.9$ \\
\hline$>10 \mathrm{~mL}$ & 39 & 18.3 & $13.1-23.5$ \\
\hline \multicolumn{4}{|c|}{ Beginning of the supplement offer after the birth of the } \\
\hline NB (hours) $\bar{X}(S D)$ & & $5.61(7.2)$ & \\
\hline
\end{tabular}

aRegistration of Time was only of bi148 newborns who received complements; $N B=$ newborn; $S D=$ standard deviation; LGA= large for gestational age. 
baby's sucking is successful, and the feeding becomes mutually beneficial for the child and the nursing mother, strengthening the mother-child bond.

The absence of colostrum or hypogalactia, reported in the literature as the main reason for early weaning, consists of reduced milk secretion. It is caused by hormonal changes in the oxytocin and prolactin - a condition often associated with biological, psychosocial, and behavioral factors, such as: the first birth, surgical procedure, pain, discomfort anxiety, stress, and prematurity. 25,26 These situations can delay hormone release and the first lactation (which usually occurs within 72 hours after birth) and, consequently, favor the maternal desire for supplementation. ${ }^{8}$ Delayed lactogenesis can also be due to inadequate grabbing, lack of sucking, and even offering infant formula in the first hours of life. 27,28 However, a careful evaluation is necessary when considering the type of delivery and parity, because in Isik and collaborators' study, 26 there was no statistically significant correlation between prolactin production and these factors.

Although, the absence of colostrum is not justifiable for the complement in offering food, studies show that if this condition is prolonged, the risk of hypoglycemia is imminent, especially in premature NBs and LGA.14,17 As much as this is one of the justifiable reasons, there is still no consensus in the literature about the offering of formulas in reducing cases of hypoglycemia in NBs, nor the definition of glycemic values that characterize it and therefore, support the indication of complement, leaving this definition to the discretion of clinical evaluation, according to the individuality of each child. ${ }^{29}$ In this study, only one third of the NBs who received the complement had glycemic record. Another limitation of the glycemic values in this study was due to the collection being done in only 3 maternity hospitals, and for this reason, we chose not to include it in the final regression model.

In healthy conditions, parturient women have biological conditions that are sufficiently favorable for breast milk production in the first hours after birth. However, mother's and the healthcare team's perception of "insufficient milk" is still frequent. This leads to the lack of adequate waiting and/or stimulation for colostrum dripping - including the absence of skin-to-skin contact and breastfeeding the NB in the first hour of life. In this study, the complement was offered, on average, 5.6 hours after birth, being this time lower than that reported in the pertinent literature ( 8.7 hours), which points out as harmful factors for EB: a longer period of profes- sional activity and maternal fatigue in the daytime. $8,19,21$

Another much discussed point is the type of complement offered. Despite the unanimity in offering breast milk the maternity that has a milk bank - two of the institutions participating in this study - did not have sufficient stock for the full-term $\mathrm{NB}$, thus prioritizing, for them, the offer of starting infant formulas.

Policies to combat the advertising and discounting infant formulas in the hospitals, as well as the harassment of these companies with medical and nutritional professionals to prescribe and purchase, may be means of manipulations to favor improper prescriptions and to decrease the offering in supplying the supplements in these settings. In Brazil, this policy was instituted by the Norma Brasileira de Comercialização de Alimentos para Lactentes e Crianças de Primeira Infância, Bicos, Chupetas e Mamadeiras (NBCAL - Lei 11.265 de

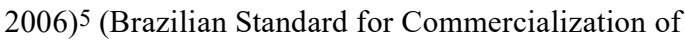
Food for Infants, Young Children, Nipples, Pacifiers and Bottles, but the effect on the use of formulas to replace breast milk in hospitals is still unknown. In this sense, strategies such as the breast milk donation campaign are fundamental to increase the stocks in HMBs and thus favor the promotion of breastfeeding. For example, there is a hospital in Hong Kong, where it was possible to reduce $57 \%$ of the supply of formula supplementation, increased $23.6 \%$ the EB during hospitalization, and increased the breastfeeding time from 8 to 12 weeks after adopting policies that do not accept free infant formula. 30

Among the limitations, it is noteworthy that the original study was not designed to exclusively evaluate the complement in offering food, which justifies the absence or incompleteness of some variables collected. For example, the sample did not include all the explanatory variables for the complement in offering food - such as the time of offering and the recording of capillary blood glucose a more in-depth analysis of the reasons for the complement in offering food at the "Child-Friendly Hospitals", the difficulties to maintain the "Ten Steps", and the evaluation of the accreditation process.

Although this study was conducted in only one city, the results of this research are consistent with the literature. At the same time, such findings are strengthened by the previous realization of a pilot study for better applicability of the research instrument and by the collection of information having been performed when NBs were exposed to the use of the complement. Thus, memory biases were minimized and allowed the confirmation and validation 
of the information recorded in the medical records

The results confirmed that maternal and care are determinants characteristics for the offer of complementary food to infants, as well as the need to protect mothers of greater vulnerability. Given the findings, this study favors the increase of knowledge about the predictors of the complement in offering food, reinforcing the need for explanations of the prescriptions, as well as the non-prescriptions (especially in maternity hospitals accredited to IHAC), to investigate whether the use of the complement in offering food contributes to early weaning in these children and the maternal desire to exclusively breastfeed.

Considering the unacceptability to offer complementary food without acceptable justifications in a "Child -Friendly Hospitals", the findings of this research strengthen the role and awareness of the team, as well as the planning and implementation of educational actions necessary to empower mothers about the mutual benefit of breast milk for the binomial. Such understanding is essential for the development of interventions that minimize the inadequate supply of the complement in offering food and promote EB. In this sense, the Politica Nacional de Atenção à Saúde da Criança - PNAISC (National Policy for Comprehensive Child Health Care) through Rede Cegonha (Stork Network) and IHAC must be firm in its principles: training the healthcare team, improving assistance in childbirth, birth and postpartum, supporting the accreditation of the IHAC and discourage the purchase of over-thecounter use of infant formula.

\section{Acknowledgments}

We would like to thank the maternity hospitals that approved and collaborated with this study, the mothers who kindly agreed to participate.

\section{Financing}

This study was financed in part by the Coordenação de Aperfeiçoamento de Pessoal de Nivel Superior Brasil (CAPES) - Finance Code 001. The financier did not interfere with the study's design and collection, analysis, and interpretation of data and writing the manuscript.

\section{Authors' contribution}

Pinheiro JMF, MenêzesFlor TB, Braga da Mata AM, Andrade FB: made substantial contributions to the conception, design, analysis and interpretation of the data as well as the writing of the article. Pires VCC, Oliveira LIC, Barbosa WPM made substantial contributions to data acquisition and writing of the article. All authors approved the final version of the manuscript.

\section{References}

1. WHO (World Health Organization). Guideline: protecting, promoting and supporting breastfeeding in facilities providing maternity and newborn services. Geneva; 2017.

2. Silva OLO, Rea MF, Venâncio SI, Buccini GS. A Iniciativa Hospital Amigo da Criança: contribuição para o incremento da amamentação e a redução da mortalidade infantil no Brasil. Rev Bras Saúde Mater Infant. 2018; 18 (3): 491-9.

3. Victora CG, Bahl R, Barros AJD, França GVA, Horton S, Krasevec J, Murch S, Sankar MJ, Walker N, Rollins NC. Breastfeeding in the 21st century: epidemiology, mechanisms, and lifelong effect. Lancet. 2016; 387 (10017): 475 90.

4. UNICEF (Fundo das Nações Unidas para a Infância). Iniciativa Hospital Amigo da Criança: revista, atualizada e ampliada para o cuidado integrado: módulo 1: histórico e implementação. UNICEF. Brasília, DF: Ministério da Saúde; 2008.

5. Brasil. Ministério da Saúde. Secretaria de Atencãoà Saúde. Departamento de Ações Programáticas Estratégicas. Bases para a discussão da política nacional de promoção, protecão e apoio ao aleitamento materno. Brasília (DF): Ministério da Saúde; 2017. [acesso 13 ago 2020]. Disponível em: https://portaldeboaspraticas.iff.fiocruz.br/biblioteca/basespara-a-discussao-da-politica-nacional-de-promocaoprotecao-e-apoio-ao-aleitamento-materno/.

6. Brasil. Lei $\mathrm{n}^{\mathrm{0}}$ 11.265, de 3 de janeiro de 2006.Regulamenta a comercialização de alimentos para lactentes e crianças deprimeira infância e também a de produtos de puericultura correlatos. Brasília, DF:Diário Oficial da União; 2006. [acesso 13 ago 2020]. Disponível em: http://www.planalto.gov.br/ccivil 03/ ato20042006/2006/lei/111265.htm

7. Saco MC, Coca KP, Marcacine KO, Abuchaim ESV, Abrão ACFV. Contato pele a pele e mamada precoce: fatores associados e influência no aleitamento materno exclusivo. Texto Contexto Enferm. 2019; 28: e20180260.

8. Pinheiro JMP, Menêzes TB, Brito KMF, Melo ANL, Queiroz DJM, Sureira TM. Prevalência e fatores associados à prescrição/solicitação de suplementação alimentar em recém-nascidos. Rev. Nutr. 2016; 29(3):367-75.

9. Da Silva JLP, Linhares FMP, Barros, AA, Souza AG, Alves DS, Andrade PON. Fatores associados ao aleitamento materno na primeira Hora de vida em um hospital amigo da criança. Texto Contexto Enferm. 2018; 27 (4): e4190017. 
10. Newhook JT, Newhook LH, Midodzi WK, Goodridge JM, Burrage L, Gill N, Halfyard B, Twells L. Determinants of NonmedicallyIndicated In-Hospital Supplementationof Infants Whose Birthing ParentsIntended to Exclusively Breastfeed.J Hum Lacta. 2017; 33 (2): 278-84.

11. Khanal V, Scott JÁ, Lee AH, Karkee R, Binn CW. The supplemental use of infant formula in the context of universal breastfeeding practices in Western Nepal. BMC Pediatrics. 2016; 16 (68): 1-7.

12. Biggs KV, Hurrell E, Khaleva E. Munblit D, Boyle RJ. Formula Milk Supplementation on the PostnatalWard: A Cross-Sectional Analytical Study. Nutrients. 2018; 10 (5) 608.

13. Zarshenas M, Zhao Y, Binns CW, Scott JA. Determinants of in-hospital feeding practices in Shiraz, Iran: Results of a prospective cohort study. Birth. 2018; 46 (1): 137-45.

14. Kelly E, DunnGalvin G, Murphy BP, Hourihane JO’B. Formula supplementation remains a risk for cow's milk allergy. Pediatr Allergy Immunol. 2019; 30 (8): 810-16.

15. Pierro J, Abulaimoun Bdair, Roth P, Blau J. Factors Associated with Supplemental Formula Feeding of Breastfeeding Infants During Postpartum. Breastfeeding Med. 2016; 11 (4): 196-202.

16. Carreiro JA, Francisco AA, Abrão AC, Marcacine KO, Abuchaim ES, Coca KP. Dificuldades relacionadas ao aleitamento materno: análise deum serviço especializado em amamentação. Acta Paul Enferm. 2018; 31 (4): 430-8.

17. Bentley JP, Nassar N, Porter M, de Vroome M, Yip E, Ampt AJ. Formula supplementation in hospital and subsequen feeding at discharge among women who intended to exclusively breastfeed: An administrative data retrospective cohort study. Birth. 2017; 44 (4): 352-62.

18. Forbes JD, Azad MB, Vehling L, Tun HM, Konya T, Guttman DS, Field CJ, Lefebvre D, Sears MR, Becker AB, Mandhane PJ, Turvey SE, Moraes TJ, Subbarao P, Scott JA, Kozyrskyj AL; Canadian Healthy Infant Longitudinal Development (CHILD) Study Investigators. Association of Exposure to Formula in the Hospital and Subsequent Infant Feeding Practices With Gut Microbiota and Risk of Overweight in the First Year of Life. JAMA Pediatr. 2018; 172 (7): e181161.

Received on October 15, 2020

Final version presented on May 27, 2021

Approved on July 15, 2021
19. Cordero L, Stenger MR, Landon MB, Nankervis CA. Inhospital formula supplementation and breastfeeding initiation in infants born to women with pregestational diabetes mellitus. J Neonatal Perinatal Med. 2019; 12 (3): 285-93.

20. Lamouniera JA, Chaves RG, Rego MAS, Bouzadac MCF. Iniciativa Hospital Amigo da Criança:25 Anos de Experiência no Brasil. Rev Paul Pediatr. 2019; 37 (4): 48693.

21. Garrison MP, Maisano P. Systematic Review of Factors Influencing Non-Medically Indicated Formula Supplementation of Newborns in the Hospital Setting. Nurs Womens Health. 2019; 23 (4): 340-50.

22. Demirci JR, Bogen DL. An Ecological Momentary Assessment of Primiparous Women's Breastfeeding Behavior and Problems From Birth to 8 Weeks. J Hum Lact. 2017; 33 (2): 285-95.

23. Leal MC; Parto e nascimento no Brasil: um cenário em processo de mudança. Cad Saúde Pública. 2018; 34 (5): $\mathrm{e} 00063818$.

24. Kair LR, Flaherman VJ. Donor Milk or Formula: A Qualitative Studdy of Postpartum Mothers of Healthy Newborn. J Hum Lact. 2017; 33 (4): 710-16.

25. Dimitraki M, Tsikouras P, Manav B, Gioka T, Koutlaki N, Zervoudis S, Galazios G. Evaluation of the effect of natural and emotional stress of labor on lactation and breastfeeding. Arch Gynecol Obstet. 2016; 293 (2): 317-28.

26. İsik Y, Dag ZO, Tulmac OB, Pek E. Early postpartum lactation effects of cesarean and vaginal birth. Ginekol Pol. 2016; 87 (6): 426-30.

27. Gasparin VA, Strada JKR, Moraes BA, Betti T, Gonçalves AC, Santo LCDE. Pairs seen by lactation consultants and cessation of exclusive breastfeeding in the first month. Rev Esc Enferm USP. 2019; 53: e03422.

28. Rocha BO. Hipogalactia inicial, fatores de risco para o desmame precoce e promoção do aleitamento materno em primíparas atendidas em um hospital amigo da criança no brasil. [dissertação]. Belo Horizonte: Universidade Federal de Minas Gerais; 2018.

29. Rozance PJ, Wolfsdorf JI. Hypoglycemia in the Newborn. Pediatr Clin North Am. 2019; 66 (2): 333-42.

30. Tarrant M, Lok KY, Fong DY, Lee IL, Sham A, Lam C, Wu KM, Bai DL, Wong KL, Wong EM, Chan NP, Dodgson JE. Effect of a hospital policy of not accepting free infant formula on in-hospital formula supplementation rates and breastfeeding duration. Public Health Nutr. 2015; 18 (14): 2689-99. 